\title{
Parameters of Cardiac Electrical Instability in Chronic Haemodialysis Patients
}

\author{
Ahmed Abdel-Galeel ${ }^{1, ~ *, ~ L o b n a ~ A b d e l-W a h i d ~}{ }^{2}$, Samir Kamal Abdulhamid ${ }^{2}$, Ahmed Obiedallah ${ }^{2}$, \\ Mohammed Aboel-Kassem Farghal Abdelmegid ${ }^{1}$, Hanan Sharaf El-Deen Mohammed ${ }^{2}$ \\ ${ }^{1}$ Cardiology Department, Assiut University Hospitals, Assiut, Egypt \\ ${ }^{2}$ Internal Medicine Department, Assiut University Hospitals, Assiut, Egypt
}

\section{Email address:}

ahmed_gelil@yahoo.com (A. Abdel-Galeel), lobna_wahid@yahoo.com (L.Abdel-Wahid), samirkotb45@yahoo.com (S. K. Abdulhamid), ahmed_obiedallah@yahoo.com (A. Obiedallah), aboelkassem1970@yahoo.com (M. Aboel-Kassem F. A.),

dr_hanansharaf@yahoo.com (H. S. El-Deen M.)

\section{To cite this article:}

Ahmed Abdel-Galeel, Lobna Abdel-Wahid, Samir Kamal Abdulhamid, Ahmed Obiedallah, Mohammed Aboel-Kassem Farghal Abdelmegid, Hanan Sharaf El-Deen Mohammed. Parameters of Cardiac Electrical Instability in Chronic Haemodialysis Patients. American Journal of Internal Medicine. Vol. 3, No. 3, 2015, pp. 78-85. doi: 10.11648/j.ajim.20150303.11

\begin{abstract}
Background: A large proportion of cardiovascular mortality in dialysis patients is caused by sudden death that is related to the dialysis procedure. Parameters of heart rate variability, P wave duration and dispersion and rate corrected QT and QT dispersion are readily used to assess cardiac electrical stability. However, there are relatively few data discussing the factors associated with arrhythmia in dialysis patients. Methods: The study included 30 patients on regular haemodialysis. All patients had full history taking (age, sex, duration of haemodialysis in months and smoking history), clinical examination, laboratory investigations (serum $\mathrm{Mg}, \mathrm{K}, \mathrm{Na}$ and complete blood picture), echocardiography and 24-hours Holter recording. Results: The study included 30 patient on regular haemodialysis (mean duration $30.9 \pm 13.2$ months), $53.3 \%$ males with mean

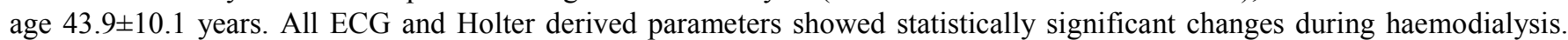
There were increase in P wave duration and dispersion, rate corrected QT interval and QT dispersion and decrease in heart rate variability, that are arrhythmogenic. Moreover, the incidence of both supraventricular and ventricular ectopics increased during dialysis. Smoking and long term dialysis were associated with more arrhythmia risk. Conclusions: Patients on regular haemodialysis are susceptible to cardiac arrhythmias. The process of haemodialysis itself is arrhythmogenic. Smoking and long term haemodialysis are associated with higher incidence of cardiac electrical instability.
\end{abstract}

Keywords: Haemodialysis, Arrhythmia, Smoking

\section{Introduction}

Dialysis patients display high rates of cardiac mortality. Heart failure develops in up to $50 \%$ of haemodialysis patients and confers a dramatic reduction in survival [1]. A large proportion of cardiovascular mortality in dialysis patients is caused by sudden death that is temporally related to the dialysis procedure, with rates highest in the 12-hours period after starting a dialysis treatment and in the predialysis period following the 3-days gap [2].

There is interest in proving the dialysis procedure to be pro-arrhythmogenic, mediated by the rapid shifts in fluid and electrolyte concentrations [3]. A large database study has recently shown that mortality attributed to sudden cardiac death was 14-fold increased among dialysis patients when compared to the general population due to high frequency of ventricular arrhythmia [4]. So early detection of high-risk individuals, particularly those susceptible to cardiac death, is of clinical importance.

Heart rate variability (HRV) refers to a measure of the beat-to-beat variations of heart beat interval. For the purpose of survival/risk prediction, HRV is analyzed using 24 hours ambulatory Holter recordings of electrocardiogram, and it is expressed as two different kinds of measures; those reflecting statistical or geometric range of the variations within certain periods of time (time-domain measures) and those reflecting magnitude (power) of cyclic components of variations within specific ranges of frequency (frequency-domain measures). The irregular behavior of the heart beat is readily apparent when heart rate is examined on a beat-to-beat basis, but is 
overlooked when a mean value over time is calculated. These fluctuations in heart rate result from complex, non-linear interactions between different physiological systems [5].

In various populations, decreased heart rate variability identifies patients at an increased risk of death, particularly that of cardiac death [6]. Recently, it has been reported that decreased HRV predicts an increased risk of death in a small cohort of chronic haemodialysis patients with angiographically proven coronary artery disease [7]. This finding has been extended to the general populations of chronic haemodialysis patients [8].

During haemodialysis, there is marked rapid shift in serum electrolyte concentration which may predispose to certain dysrrhythmic events. Premature atrial ectopic activities may present abundantly during haemodialysis that may degenerate into atrial tachyarrhythmia such as atrial fibrillation. In haemodialysis patients, AF occurred significantly more often on a dialysis day and especially during dialysis session [9]. Moreover, haemodialysis ends with significant increase in $\mathrm{P}$ wave maximum duration and $\mathrm{P}$ wave dispersion, which might be responsible for the increased occurrence of atrial fibrillation in these groups of patients [10].

Prolongation of the QT interval predisposes to torsade de pointes ventricular tachycardia. While many episodes may be self terminating, torsade can degenerate into lethal ventricular fibrillation [11]. In nonuremic patients, episodes of torsade de pointes often occur due to a combination of factors, including prolonged QTc with bradycardia, pauses, some medications or electrolyte abnormalities such as hypokalemia, hypomagnesemia or hypocalcemia. QT dispersion (maximum minus minimum QTc interval on a standard 12-lead electrocardiogram) is also taken as a risk factor for ventricular arrhythmias and sudden death [12]. Several authors have reported an acute increase in both QTc and QT dispersion following dialysis [13]. Moreover, studies using ambulatory electrocardiogram have demonstrated an increased rate of ventricular arrhythmia during dialysis [14].

However, there are relatively few data discussing the factors associated with arrhythmia in dialysis patients. In a recent study conducted on patients with chronic kidney disease, ventricular arrhythmia was prevalent in pre-dialysis patients. Aging, increased hemoglobin levels and reduced ejection fraction were the factors independently associated with the presence of ventricular arrhythmia in those patients [15].

\section{Aim of the Study}

To detect the pure effects of haemodialysis on cardiac electrical status both atrial and ventricular as assessed by Holter monitoring and to evaluate the effects of smoking and prolonged duration of dialysis on arrhythmia risk.

\section{Patients and Methods}

30 patients with end-stage renal disease who are on regular haemodialysis for at least 4 hours three times per week for at least the last 6 months were studied. The haemodialysis is carried out using BC-F - liquid bicarbonate concentrate $8.4 \%$ (Fresenius Medical Care Deutschland GmbH, Bad Homburg, Germany) which is the standard in dialysis unit, Assiut University Hospitals.

The study was approved by the ethical committee of Assiut Faculty of Medicine. A written consent was taken from every participant. All the study patients were subjected to the followings:

(1) Full history taking including age, sex, duration of haemodialysis in months and smoking history.

The fulfilled medical history also included possible history of ischaemic heart disease as detected by typical ischaemic chest pain, prior myocardial infarction or unstable angina, prior PCI or CABG. We asked also about history of diabetes mellitus or any drug intake that affects heart rate, QT interval or heart rate variability.

(2) Clinical examination including heart rate and blood pressure assessment half an hour after beginning of HD.

(3) Laboratory assessment: This included serum $\mathrm{Mg}, \mathrm{K}$ and $\mathrm{Na}$ levels and complete blood picture. The laboratory assessment was done immediately before dialysis.

(4) Echocardiography: done before haemodialysis to obtain left atrial, left and right ventricular dimensions. Also to calculate left ventricular systolic function and assess the diastolic function.

(5) Holter monitoring: done for 24 hours for the day of haemodialysis. The recording began at least six hours before haemodialysis and for 24 hours. The following parameters would be obtained for Holter monitoring before, during and after haemodialysis:

a. Maximum, minimum and average heart rate and heart rate variability.

b. Parameters of atrial electrical activity including: P wave duration and $\mathrm{P}$ wave dispersion.

c. Parameters of ventricular electrical activity including: QTc interval and QT dispersion.

d. Any premature ectopic activity either atrial or ventricular.

Exclusion criteria included history of ischaemic heart disease, diabetes mellitus, drugs that affects the cardiac autonomic function or affect QT interval. Also patients with atrial fibrillation, those with impaired left ventricular systolic function, anaemia and with serum electrolyte abnormalities were excluded.

\section{Results}

The study is a prospective study involved 30 patients with documented end-stage renal disease and already on regular dialysis therapy. The study was conducted in Assiut University Hospital during the period between $1^{\text {st }}$ June and $31^{\text {st }}$ August 2014.

(1) Baseline data: The following table shows the demographic, baseline clinical, laboratory, electrocardiographic and echocardiographic criteria of the study population. 
Table (1). Demographic, baseline clinical, laboratory, electrocardiographic and echocardiographic criteria of the study population.

\begin{tabular}{|c|c|}
\hline \multicolumn{2}{|l|}{ Parameter } \\
\hline Age (years, mean \pm SD) & $43.9 \pm 10.1$ \\
\hline Sex $($ male \%) & 53.3 \\
\hline Smoking (\%) & 30.0 \\
\hline Dialysis period (months, mean \pm SD) & $30.9 \pm 13.2$ \\
\hline Heart rate (beat/min, mean \pm SD) & $80.2 \pm 11.4$ \\
\hline Systolic blood pressure $(\mathrm{mmHg}$, mean $\pm \mathrm{SD})$ & $154.1 \pm 17$ \\
\hline Diastolic blood pressure $(\mathrm{mmHg}$, mean $\pm \mathrm{SD})$ & $89.5 \pm 11.6$ \\
\hline Serum $\mathrm{Na}^{+}(\mathrm{mmol} / \mathrm{L}$, mean $\pm \mathrm{SD})$ & $138.3 \pm 7.2$ \\
\hline Serum $\mathrm{Mg}^{++}(\mathrm{mmol} / \mathrm{L}$, mean $\pm \mathrm{SD})$ & $1.9 \pm 0.4$ \\
\hline Serum $\mathrm{Ka}^{+}(\mathrm{mmol} / \mathrm{L}$, mean $\pm \mathrm{SD})$ & $4.7 \pm 0.7$ \\
\hline $\mathrm{P}$ wave duration (msec., mean $\pm \mathrm{SD}$ ) & $100.9 \pm 9.0$ \\
\hline $\mathrm{P}$ wave dispersion (msec., mean $\pm \mathrm{SD}$ ) & $48.4 \pm 8.2$ \\
\hline QTc interval (msec., mean \pm SD) & $403.4 \pm 17.8$ \\
\hline QT dispersion (msec., mean \pm SD) & $76.8 \pm 10.0$ \\
\hline Left atrial AP diameter $(\mathrm{mm}$, mean \pm SD) & $3.9 \pm 0.7$ \\
\hline
\end{tabular}

\begin{tabular}{ll}
\hline Parameter & \\
\hline Left ventricular end-diastolic diameter $(\mathrm{mm}$, mean $\pm \mathrm{SD})$ & $5.4 \pm 1.1$ \\
Left ventricular end-systolic diameter $(\mathrm{mm}, \mathrm{mean} \pm \mathrm{SD})$ & $3.1 \pm 1.0$ \\
Left ventricular ejection fraction $(\%$, mean $\pm \mathrm{SD})$ & $59 \pm 8$ \\
Right ventricular end-diastolic diameter $(\mathrm{mm}, \mathrm{mean} \pm \mathrm{SD})$ & $1.7 \pm 0.9$ \\
\hline
\end{tabular}

(2) Holter Data: The Holter data were collected for the 30 patients. The Holter recording started at 9 AM the day of dialysis and continued for 24 hours. The recorded period was divided for descriptive purpose into three time intervals as follow:

(a) Pre-dialysis: included at least 6 hours interval before haemodialysis.

(b) Haemodialysis: included at least four hours interval, the period of haemodialysis.

(c) Post-dialysis: included the rest of recorded period.

Table (2). Holter-derived parameters for the study population.

\begin{tabular}{|c|c|c|c|c|}
\hline Parameter & Pre-Dialysis & Dialysis & Post-Dialysis & P value \\
\hline Heart rate (beat/min, mean \pm SD) & $78.8 \pm 10.5$ & $76.7 \pm 9.4$ & $76.2 \pm 8.3$ & 0.3 \\
\hline P wave duration (msec., mean \pm SD) & $95.1 \pm 10.2$ & $97.5 \pm 11.2$ & $87.8 \pm 7.3$ & 0.001 \\
\hline $\mathrm{P}$ wave dispersion (msec., mean $\pm \mathrm{SD}$ ) & $47.7 \pm 8.3$ & $47.5 \pm 7.8$ & $44.3 \pm 6.0$ & 0.004 \\
\hline QTc interval (msec., mean \pm SD) & $454.1 \pm 13.5$ & $459.1 \pm 11.0$ & $443.9 \pm 10.0$ & 0.001 \\
\hline QT dispersion (msec., mean \pm SD) & $88.3 \pm 9.1$ & $92.7 \pm 5.7$ & $81.8 \pm 7.3$ & 0.001 \\
\hline Supraventricular ectopics (n/h) & $16.2 \pm 8.8$ & $23.0 \pm 11.4$ & $11.7 \pm 6.6$ & 0.001 \\
\hline Heart rate variability (SDNN in msec.) & $113.0 \pm 23.0$ & $103.0 \pm 19.9$ & $116.1 \pm 19.3$ & 0.001 \\
\hline
\end{tabular}

Table (3). Effect of smoking on cardiac electrical stability among the dialysis patients.

\begin{tabular}{|c|c|c|c|}
\hline Parameter & Group (A) & Group (B) & P value \\
\hline Pre HD Heart rate (beat/min, mean \pm SD) & $76.0 \pm 10.6$ & $80.1 \pm 10.5$ & 0.3 \\
\hline HD Heart rate (beat/min, mean \pm SD) & $73.1 \pm 7.1$ & $78.2 \pm 10.0$ & 0.1 \\
\hline Post HD Heart rate (beat/min, mean \pm SD) & $71.1 \pm 6.8$ & $78.4 \pm 8.0$ & 0.02 \\
\hline Pre HD P wave duration (msec., mean \pm SD) & $104.0 \pm 7.6$ & $91.2 \pm 8.7$ & 0.001 \\
\hline HD P wave duration (msec., mean \pm SD) & $107.8 \pm 12.3$ & $93.1 \pm 7.4$ & 0.001 \\
\hline Post HD P wave duration (msec., mean \pm SD) & $93.8 \pm 8.3$ & $85.2 \pm 5.3$ & 0.002 \\
\hline HD P wave dispersion (msec., mean \pm SD) & $54.7 \pm 8.4$ & $44.4 \pm 5.2$ & 0.001 \\
\hline Post HD P wave dispersion (msec., mean $\pm \mathrm{SD}$ ) & $49.1 \pm 8.1$ & $42.3 \pm 3.5$ & 0.003 \\
\hline Pre HD QTc interval (msec., mean \pm SD) & $453.1 \pm 13.6$ & $454.5 \pm 13.8$ & 0.8 \\
\hline HD QTc interval (msec., mean \pm SD) & $460.7 \pm 12.9$ & $458.4 \pm 10.3$ & 0.6 \\
\hline Post HD QTc interval (msec., mean \pm SD) & $444.2 \pm 13.2$ & $443.7 \pm 8.7$ & 0.9 \\
\hline Pre HD QT dispersion (msec., mean \pm SD) & $90.7 \pm 11.0$ & $87.2 \pm 8.3$ & 0.3 \\
\hline HD QT dispersion (msec., mean \pm SD) & $95.3 \pm 6.9$ & $91.6 \pm 4.9$ & 0.1 \\
\hline Pre HD Supraventricular ectopics (n/h) & $21.9 \pm 10.0$ & $13.7 \pm 7.1$ & 0.016 \\
\hline HD Supraventricular ectopics (n/h) & $31.1 \pm 12.1$ & $19.6 \pm 9.4$ & 0.008 \\
\hline Post HD Supraventricular ectopics (n/h) & $16.9 \pm 8.2$ & $9.4 \pm 4.2$ & 0.003 \\
\hline Pre HD Ventricular ectopics (n/h) & $11.8 \pm 4.8$ & $10.9 \pm 3.8$ & 0.6 \\
\hline HD Ventricular ectopics (n/h) & $21.4 \pm 6.9$ & $13.6 \pm 5.0$ & 0.002 \\
\hline Post HD Ventricular ectopics (n/h) & $10.0 \pm 4.2$ & $8.2 \pm 3.0$ & 0.2 \\
\hline Pre HD Heart rate variability (SDNN in $\mathrm{msec}$ ) & $91.6 \pm 14.8$ & $122.2 \pm 19.5$ & 0.001 \\
\hline HD Heart rate variability (SDNN in msec) & $93.1 \pm 12.9$ & $107.3 \pm 21.1$ & 0.03 \\
\hline Post HD Heart rate variability (SDNN in msec) & $97.1 \pm 15.2$ & $124.3 \pm 14.6$ & 0.001 \\
\hline
\end{tabular}

(3) Effects of the haemodialysis session on arrhythmic events:

Despite the statistically insignificant change in heart rate, there is a statistically significant difference in all other
Holter-acquired parameters. Using repeated Anova test, the period of haemodialysis has been proved to be arrhythmogenic in terms of atrial and ventricular electrical instability. P wave duration and dispersion and QTc interval 
and dispersion were prolonged during haemodialysis. Also the incidence of premature atrial and/or ventricular ectopic activities increased during haemodialysis. Moreover, the heart rate variability was greatly impaired during haemodialysis rendering those patients more susceptible for malignant arrhythmias.

(4) Factors associated with arrhythmic events during haemodialysis:

There was no age nor sex difference in the incidence of arrhythmic events among dialysis patients. Moreover, serum electrolytes had no effect on Holter-derived parameters.

(1) Smoking: According to history of smoking, we divided the studied population into two groups;

(1) Group (A) included 9 smoker patients (30\%)

(2) Group (B) included 21 non smoker patients (70\%).

There was statistically significant difference in most Holter-derived data accusing smoking to be associated with arrhythmia risk among chronic haemodialysis patients.

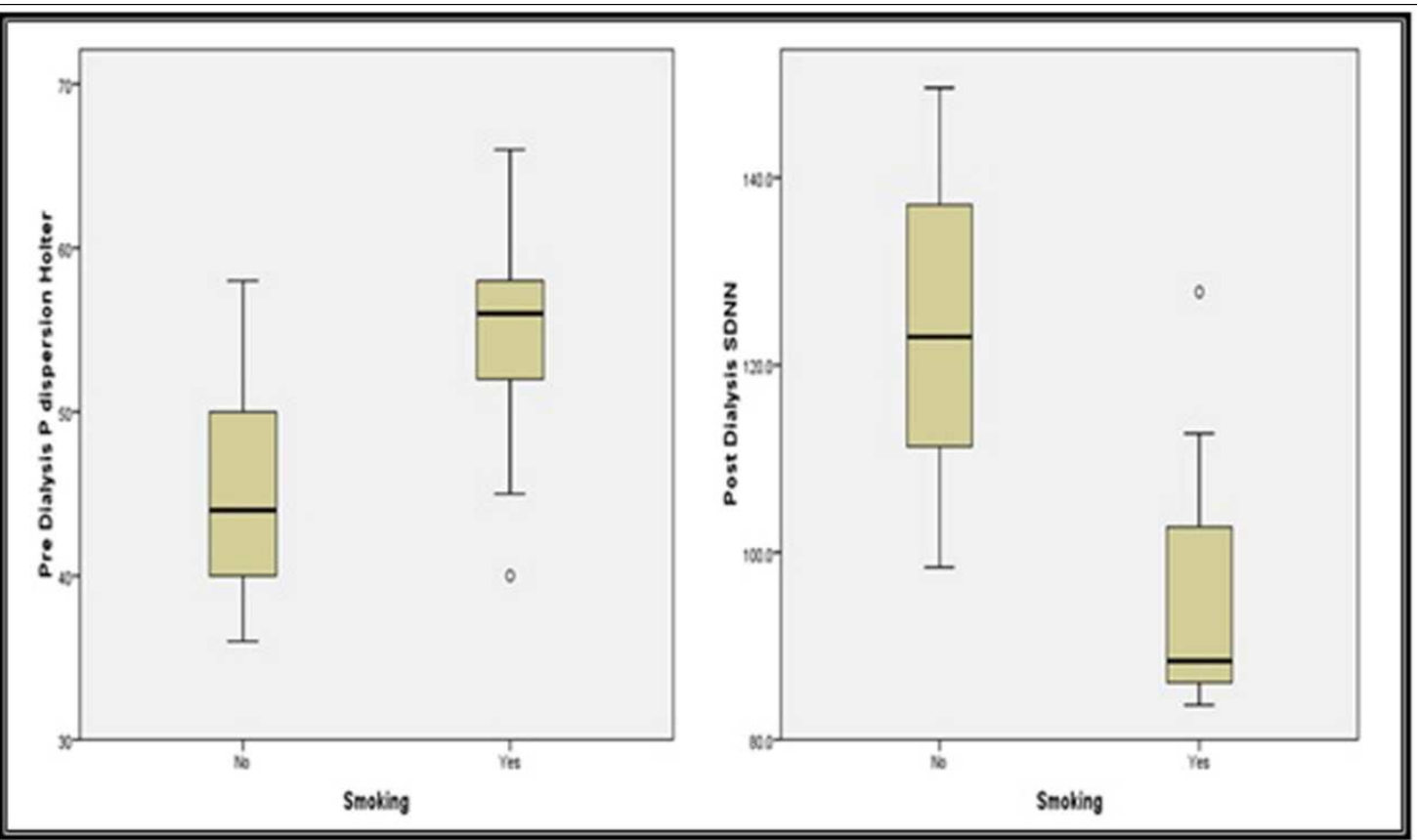

Figure (1). Effect of smoking on some Holter parameters.

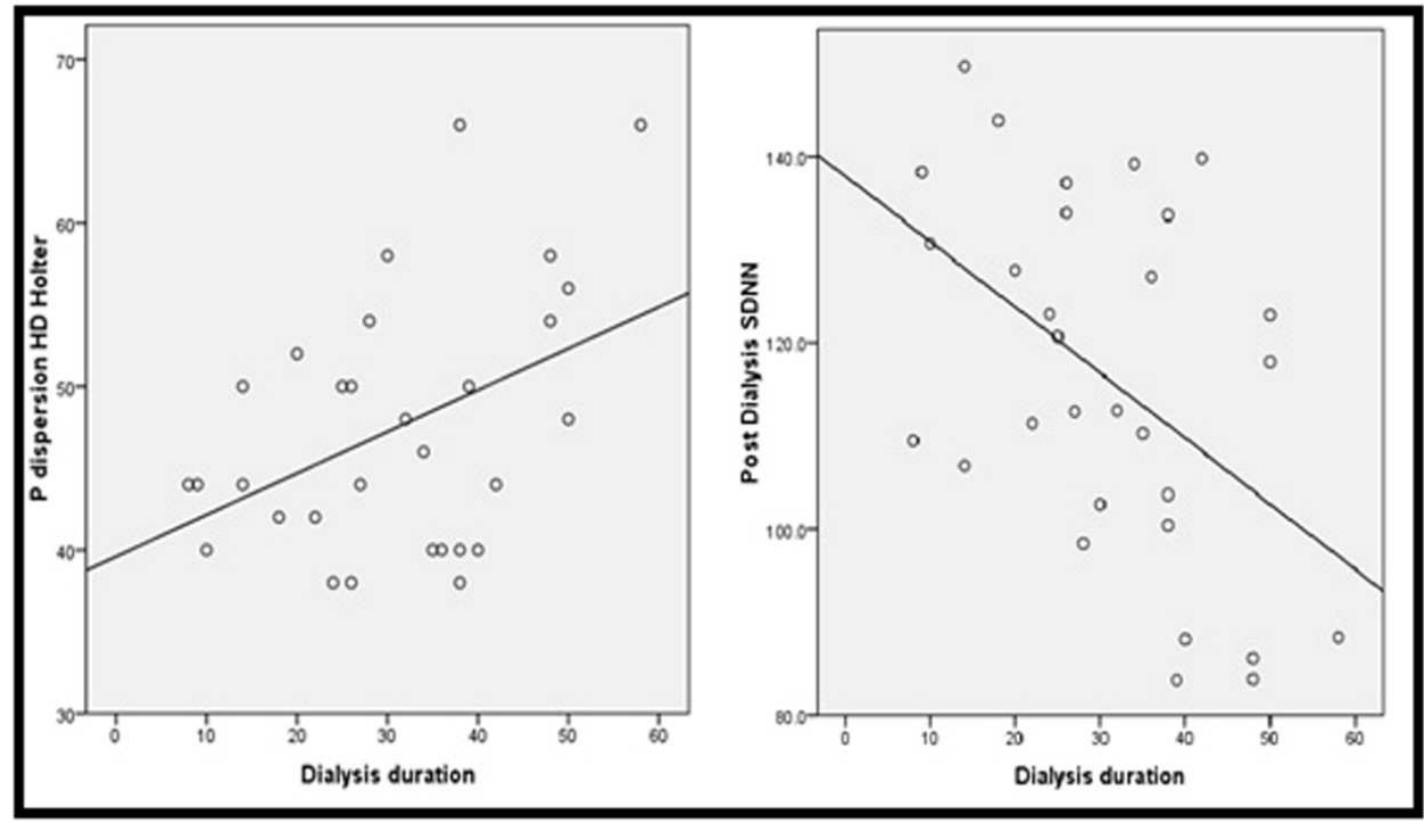

Figure (2). Relation between duration of haemodialysis and $P$ wave dispersion and heart rate variability.

(2) Duration of dialysis:

Using Pearson correlation coefficient, there was statistically significant positive correlation between duration of haemodialysis and $\mathrm{P}$ wave duration, dispersion, QTc interval, $\mathrm{QT}_{\mathrm{C}}$ dispersion, presence of premature electrical activity in both atria and ventricles. However, there was 
statistically significant negative correlation between duration of haemodialysis and heart rate variability evidenced by SDNN.

Table (4). Relation between duration of haemodialysis and Holter data.

\begin{tabular}{|c|c|c|}
\hline Parameter & $\mathbf{r}$ & P value \\
\hline Pre HD Heart rate (beat/min, mean \pm SD) & -0.1 & 0.5 \\
\hline HD Heart rate (beat/min, mean \pm SD) & -0.2 & 0.3 \\
\hline Post HD Heart rate (beat/min, mean \pm SD) & -0.3 & 0.08 \\
\hline Pre HD P wave duration (msec., mean \pm SD) & 0.3 & 0.06 \\
\hline HD P wave duration (msec., mean \pm SD) & 0.4 & 0.05 \\
\hline Post HD P wave duration (msec., mean \pm SD) & 0.5 & 0.01 \\
\hline Pre HD P wave dispersion (msec., mean \pm SD) & 0.4 & 0.05 \\
\hline HD P wave dispersion (msec., mean \pm SD) & 0.4 & 0.02 \\
\hline Post HD P wave dispersion (msec., mean \pm SD) & 0.4 & 0.03 \\
\hline Pre HD QTc interval (msec., mean \pm SD) & 0.2 & 0.2 \\
\hline HD QTc interval (msec., mean \pm SD) & 0.4 & 0.06 \\
\hline Post HD QTc interval (msec., mean \pm SD) & 0.3 & 0.2 \\
\hline Pre HD QT dispersion (msec., mean \pm SD) & 0.5 & 0.01 \\
\hline HD QT dispersion (msec., mean \pm SD) & 0.4 & 0.04 \\
\hline Post HD QT dispersion (msec., mean \pm SD) & 0.6 & 0.001 \\
\hline Pre HD Supraventricular ectopics (n/h) & 0.4 & 0.02 \\
\hline HD Supraventricular ectopics $(\mathrm{n} / \mathrm{h})$ & 0.3 & 0.06 \\
\hline Post HD Supraventricular ectopics (n/h) & 0.4 & 0.02 \\
\hline Pre HD Ventricular ectopics $(\mathrm{n} / \mathrm{h})$ & 0.6 & 0.001 \\
\hline HD Ventricular ectopics (n/h) & 0.7 & 0.001 \\
\hline Post HD Ventricular ectopics (n/h) & 0.7 & 0.001 \\
\hline Pre HD Heart rate variability (SDNN in msec) & -0.3 & 0.1 \\
\hline HD Heart rate variability (SDNN in msec) & -0.04 & 0.8 \\
\hline Post HD Heart rate variability (SDNN in $\mathrm{msec}$ ) & -0.5 & 0.007 \\
\hline
\end{tabular}

\section{Discussion}

Haemodialysis provides a treatment for patients with end stage renal disease. Thousands of patients all over the world are surviving and achieving reasonable quality of life on maintenance dialysis.

Despite recent progress in haemodialysis, mortality is still high in patients with end-stage renal disease on chronic haemodialysis. Recent studies have reported that this is due to an increasing prevalence of cardiac complications in this population [16]. Sudden cardiac death is the most common form of death in dialysis patients, accounting for $20 \%$ to $30 \%$ of all deaths in this cohort [17]. In the 2006 United States Renal Data System (USRDS) database, cardiovascular mortality is 30 times higher among dialysis patients than in matched individuals from the general population, and the risk for arrhythmogenic death is one of the highest in any population. Arrhythmia-related deaths are reported in $58 \%$ of cardiac deaths among peritoneal dialysis and $64 \%$ of cardiac deaths among haemodialysis patients [18].

Haemodialysis patients have frequent electrolyte abnormalities, such as highly fluctuating levels of potassium, calcium, magnesium and other divalent ions [19]. Due to the intermittent nature of the dialysis procedure, patients on haemodialysis also have wide fluctuations in volume status, bicarbonate and sodium levels, during and between dialysis treatments [20]. These fluctuations are partly driven by the level of potassium, sodium and calcium in the dialysate bath, as well as by a wide variability in eating habits and varying adherence to dietary prescriptions to control phosphate, calcium and sodium intake [21]. All of these factors contribute to a potentially "arrhythmogenic milieu" Identification of high-risk individuals, particularly those susceptible to cardiac death, is of clinical importance. There are many parameters to assess the arrhythmogenic risk in those high risk patients.

$\mathrm{P}$ wave duration and dispersion have been attributed to the atrial action potential. An increase in P-wave maximum duration and dispersion during haemodialysis session has been described. This may be responsible for the increased occurrence of atrial fibrillation. [10]. This phenomenon has been interpreted as a sign of intra-atrial conduction slowing. Moreover, the frequent occurrence of supraventricular ectopic beats during haemodialysis sessions may trigger $\mathrm{AF}$ episodes in a situation that is already highly favorable for the onset of arrhythmias [22].

In our study, despite the statistically insignificant change in heart rate, there is a statistically significant difference in all parameters of atrial electrical activity. $\mathrm{P}$ wave duration and dispersion were prolonged during haemodialysis. Also the incidence of premature atrial ectopic activities increased during haemodialysis.

In non uremic patients, episodes of torsade de pointes often occur due to a combination of factors, including a long QTc with bradycardia or pauses, or electrolyte abnormalities such as hypokalemia, hypomagnesemia or hypocalcemia, factors commonly associated with dialysis process. [3] End stage renal disease patients incur into sudden changes in plasma electrolyte concentrations during the haemodialysis session probably resulting in changes in the myocardial cells' action potential [23]. For this reason, haemodialysis represents a unique human model to test in vivo the effects of rapid changes in plasma electrolytes and the analysis of acute electrocardiographic alterations induced by haemodialysis may contribute to clarify the mechanisms involved in the genesis of cardiac arrhythmias [22]. QT dispersion (maximum minus minimum QTc interval on a standard 12lead electrocardiogram) is also taken as a risk factor for ventricular arrhythmias and sudden death [12]. Several authors have reported an acute increase in both QTc and QT dispersion during haemodialysis [17, 24]. Although this would support the increase in sudden death related to the dialysis procedure, there are relatively few data showing a direct link between increased QTc or QT dispersion induced by dialysis and either arrhythmia or sudden death [21]. Moreover, some authors report a heterogenic effects of haemodialysis on both QTc or QT dispersion [13, 25]. The heterogenic effect of dialysis on QT interval is mirrored in the wide range of reported frequency of dialysis-induced arrhythmias, which occur anywhere between $<5 \%$ and $90 \%$ of dialysis treatments [3].

Our study reported a statistically significant increase in both QTc and QT dispersion during haemodialysis session in comparison to pre-and post-dialysis periods. This was directly reflected on the frequency of premature ventricular 
ectopic activities that increased during dialysis session.

Heart rate variability provides a non-invasive method for investigating autonomic input into the heart. It quantifies the amount by which the R-R interval or heart rate changes from one cardiac cycle to the next. In normal individuals, without cardiac disease, the heart rate has a high degree of beat-tobeat variability. heart rate variability fluctuates with respiration, that is primarily mediated by parasympathetic activity. Higher values of heart rate variability are associated with functionally efficient autonomic control. Heart rate variability has been used to evaluate the risk of sudden cardiac death in a variety of conditions including cardiac disorders, stroke, multiple sclerosis, end stage renal disease, neonatal distress, and diabetes [26].

Studies of heart rate variability and end-stage renal disease patients have shown a decrement in heart rate variability. Vita et al. [27] demonstrated in 30 uraemic patients that $53 \%$ of patients had autonomic dysfunction reflected as diminished heart rate variability. Moreover, Fukuta et al. [8] in a prospective large study included 120 patients on regular haemodialysis, reported that decrease in some heart rate variability measures, particularly those reflecting long-term variability, are independent predictors of cardiac death during long term follow-up in patients on chronic haemodialysis.

Our study reported a temporary decrement in heart rate variability during haemodialysis session that was nearly returned to its pre-dialysis value after haemodialysis. Though the decrease in heart rate variability was statistically evident, it was not as low as to cause serious arrhythmia or worse outcome. We reported intradialytic SDNN about $103 \mathrm{msec}$. compared to 113 and $116 \mathrm{msec}$. pre- and post-dialysis respectively. This was also previously reported by Tong and Hou [28]. They stated that some heart rate variability parameters are particularly sensitive to the haemodialysis procedure. SDNN was significantly reduced during the 3 hours of dialysis and recovered 2 hours after haemodialysis to values similar to pre-dialytic period.

Our study highlighted the arrhythmogenic character of intradialytic interval. This is demonstrated by intra-dialytic increased $\mathrm{P}$ wave duration and dispersion, prolonged QTc and QTc dispersion, decrease in heart rate variability and increased frequency of both supraventricular and ventricular ectopics. However, the most arrhythmogenic period responsible for sudden cardiac death among haemodialysis patients is still a matter of debate. It is not clear whether the process of dialysis itself causes sudden cardiac death or not. Epidemiological data shows an increased risk during the 12hour period after the onset of dialysis. This involves the dialysis and early post-dialysis periods [29]. Moreover, Studies using ambulatory electrocardiogram have demonstrated an increased rate of ventricular arrhythmia during dialysis. [30].

Our study showed that smoking was linked to increase arrhythmic risk during dialysis. It is of note that smoking is a highly significant risk factor of death during the first 90 days on haemodialysis [31]. Conversely, the prevalence of active smokers among long-term survivors on haemodialysis is low
(11.8\%) [32]. The analysis of 936 haemodialysis patients enrolled in the baseline phase of the haemodialysis study sponsored by the US National Institutes of Health revealed that smoking is strongly associated with cardiovascular disease among haemodialysis patients [33]. Though, the relation between smoking and cardiovascular risk in haemodialysis patients is well established in many literatures, few, if any, discussed the relation between smoking and arrhythmia risk in the same cohort.

Our results also stated that prolonged duration of dialysis is associated with arrhythmia risk. In a recent study conducted on 150 haemodialysis patients who underwent 48hours Holter monitoring, prolonged duration of haemodialysis was associated with frequent premature ventricular ectopics [34]. On contrast, a small study carried out on 18 patients using Holter monitoring demonstrated that duration of haemodialysis has no effect on occurrence of complex ventricular arrhythmias during haemodialysis [35]. However, the small study size doubts the credibility of the study and made the statistical bias undeniable.

\section{Conclusions}

Patients on regular haemodialysis are susceptible to cardiac arrhythmias either atrial or ventricular. The process of haemodialysis itself is arrhythmogenic. Smoking and long term haemodialysis were shown to be associated with higher incidence of cardiac electrical instability. Further large scale multicentre trials should be encouraged to detect other possible arrhythmia-related factors among patients on regular haemodialysis.

\section{References}

[1] Harnett JD, Foley RN, Kent GM, Barre PE, Murray D, Parfrey PS. Congestive heart failure in dialysis patients: prevalence, incidence, prognosis and risk factors. Kidney Int 1995; $47: 884-890$.

[2] Bleyer AJ, Hartman J, Brannon PC, Reeves-Daniel A, Satko SG, Russell G. Characteristics of sudden death in hemodialysis patients. Kidney Int 2006; 69:2268-2273.

[3] Selby NM. and Mc Intyre CW: The Acute Cardiac Effects of Dialysis. Seminars in Dialysis. 2007; 20: 220-228.

[4] Roberts MA, Polkinghorne KR, McDonald SP, Ierino FL. Secular trends in cardiovascular mortality rates of patients receiving dialysis compared with the general population. Am J Kidney Dis 2011; 58: 64-72.

[5] Reyes Del Paso GA, Langewitz W, Mulder LJM, Van Roon A, Duschek S. The utility of low frequency heart rate variability as an index of sympathetic cardiac tone :a review with emphasis on a reanalysis of previous studies. Psychophysiology 2013; 50: 477-487.

[6] Bigger JT, Fleiss JL, Steinman RC, Rolnitzky LM, Kleiger RE, Rottman JN. Frequency domain measures of heart period variability and mortality after myocardial infarction. Circulation 1992; 85: 164-171. 
[7] Hayano J, Takahashi H, Toriyama T, Mukai S, Okada A, Sakata S, Yamada A, Ohte N, Kawahara H. Prognostic value of heart rate variability during long-term follow-up in chronic haemodialysis patients with end-stage renal disease. Nephrol Dial Transplant 1999; 14: 1480-1488

[8] Fukuta H, Hayano J, Ishihara S, Sakata S, Mukai S, Ohte N, Ojika K, Yagi K, Matsumoto H, Sohmiya S, Kimura G. Prognostic value of heart rate variability in patients with endstage renal disease on chronic haemodialysis. Nephrol Dial Transplant. 2003; 18: 318-325.

[9] Buiten MS, de Bie MK, Rotmans JI, Gabreëls BA, van Dorp W, Wolterbeek R, Trines SA, Schalij MJ, Jukema JW, Rabelink TJ, van Erven L. The dialysis procedure as a trigger for atrial fibrillation: new insights in the development of atrial fibrillation in dialysis patients. Heart. 2014; 100: 685-690.

[10] Tezcan UK, Amasyali B, Can I, Aytemir K, Köse S, Yavuz I, Kursaklioglu H, Işik E, Demirtaş E, Oto A. Increased P wave dispersion and maximum $\mathrm{P}$ wave duration after hemodialysis. Ann Noninvasive Electrocardiol. 2004; 9: 34-38.

[11] Gowda RM, Khan IA, Wilbur SL, Vasavada BC, Sacchi TJ. Torsade de pointes: the clinical considerations. Int J Cardiol. 2004; 96:1-6.

[12] Pye M, Quinn AC, Cobbe SM: QT interval dispersion: a noninvasive marker of susceptibility to arrhythmia in patients with sustained ventricular arrhythmias? Br Heart J 1994; 71: 511-514.

[13] Maule S, Veglio M, Mecca F, Calvo C, Martina G, Marangella M, Quadri R, Cavallo Perin P. Autonomic neuropathy and QT interval in hemodialysed patients. Clin Auton Res 2004; 14: 233-239.

[14] Burton JO, Korsheed S, Grundy BJ, McIntyre CW. Hemodialysis induced left ventricular dysfunction is associated with an increase in ventricular arrhythmias. Renal Failure 2008; 30: 701-709.

[15] Bonato FO, Lemos MM, Cassiolato JL, Canziani ME. Prevalence of ventricular arrhythmia and its associated factors in nondialyzed chronic kidney disease patients. PLoS One. 2013; 8 (6) : e66036.

[16] Kimura $G$, Tomita $J$, Nakamura $S$, Uzu $T$, Inenaga $T$. Interaction between hypertension and other cardiovascular risk factors in survival of hemodialyzed patients. Am J Hypertens 1996; 9: 1006-1012

[17] Genovesi S, Valsecchi MG, Rossi E, Pogliani D, Acquistapace I, De Cristofaro V, Stella A, Vincenti A. Sudden death and associated factors in a historical cohort of chronic haemodialysis patients. Nephrol Dial Transplant. 2009; 24: $2529-2536$.

[18] Tonelli M, Wiebe N, Culleton B, House A, Rabbat C, Fok M, McAlister F, Garg AX. Chronic kidney disease and mortality risk: a systematic review. J Am Soc Nephrol. 2006; 17: 20342047.

[19] Foley RN, Parfrey PS, Harnett JD, Kent GM, Hu L, O'Dea R, Murray DC, Barre PE. Hypocalcemia, morbidity and mortality in end-stage renal disease. Am J Nephrol. 1996; 16: 386-393.

[20] Saran R, Bragg-Gresham JL, Rayner HC, Goodkin DA, Keen ML, Van Dijk PC, Kurokawa K, Piera L, Saito A, Fukuhara S, Young EW, Held PJ, Port FK. Nonadherence in hemodialysis: associations with mortality, hospitalization, and practice patterns in the DOPPS. Kidney Int. 2003; 64: 254-262.

[21] Hecking E, Bragg-Gresham JL, Rayner HC, Pisoni RL, Andreucci VE, Combe C, Greenwood R, McCullough K, Feldman HI, Young EW, Held PJ, Port FK. Haemodialysis prescription, adherence and nutritional indicators in five European countries: results from the Dialysis Outcomes and Practice Patterns Study (DOPPS). Nephrol Dial Transplant. 2004; 19: 100-107.

[22] Severi S, Pogliani D, Fantini G, et al. Alterations of atrial electrophysiology induced by electrolyte variations: combined computational and P-wave analysis. Europace 2010; 12: 842849.

[23] Severi S, Grandi E, Pes C, Fabbrini P, Vigano `MR, Galbiati E, Bonforte G, Vincenti A, Stella A, Genovesi S. Calcium and potassium changes during haemodialysis alter ventricular repolarization duration: in vivo and in silico analysis. Nephrol Dial Transplant 2008; 23: 1378-1386.

[24] Yetkin E, Ileri M, Tandogan I, Boran M, Yanik A, Hisar I, Kutlu M, Cehreli S, Korkmaz S, Goksel S. Increased QT interval dispersion after hemodialysis: role of peridialytic electrolyte gradients. Angiology 2000; 51:499-504.

[25] Covic A, Diaconita M, Gusbeth-Tatomir P, Covic M, Botezan A, Ungureanu G, Goldsmith DJ. Haemodialysis increases QTc interval but not QTc dispersion in ESRD patients without manifest cardiac disease. Nephrol Dial Transplant 2002; 17: 2170-2177.

[26] Kleiger RE, Stein PK, Bigger JT. Heart rate variability: measurement and clinical utility. Ann Noninvasive Electrocardiol 2005; 10: 88-101.

[27] Vita G, Bellinghieri G, Trusso A, Costantino G, Santoro D, Monteleone F, Messina C, Savica V. Uraemic autonomic neuropathy studied by spectral analysis of heart rate. Kidney Int 1999; 56: 232-237

[28] Tong YQ, Hou HM. Alteration of heart rate variability parameters in nondiabetic haemodialysis patients. Am J Nephrol 2007; 27: 63-69

[29] Bleyer A, Hartman J, Brannon PC, Satko SG. Characteristics of sudden death in hemodialysis patients. Kidney Int 2006; 88: $2268-2273$.

[30] Burton JO, Korsheed S, Grundy BJ, McIntyre CW. Hemodialysis induced left ventricular dysfunction is associated with an increase in ventricular arrhythmias. Renal Failure 2008; 30: 701-709.

[31] Khan IH, Catto GR, Edward N, MacLeod AM. Death during the first 90 days of dialysis: a case control study. Am J Kidney Dis 1995; 25: 276-280.

[32] Owen WF, Madore F, Brenner BM. An observational study of cardiovascular characteristics of long-term end-stage renal disease survivors. Am J Kidney Dis 1996; 28: 931-936.

[33] Cheung AK, Sarnak MJ, Yan G, Dwyer JT, Heyka RJ, Rocco MV, Teehan BP, Levey AS. Atherosclerotic cardiovascular disease risks in chronic hemodialysis patients. Kidney Int 2000; 58: 353-362.

[34] Saygi S, Asci G, Dheir H, Duman S, Kayikcioglu M, Yilmaz M, Ozkahya M, Ok E. Ventricular arrhythmia in dialysis patients: a link with higher hemoglobin levels? Hemodial Int. 2011; 15: 250-255. 
[35] Shimizu Y, Koro T, Koyama A. Patients with complex ventricular arrhythmias during hemodialysis suffer from unstable blood pressure. Internet J Nephrol 2004 Volume 2 Number 1. 